\title{
Endogenous hydrogen sulfide mediates the cardioprotection induced by ischemic postconditioning in the early reperfusion phase
}

\author{
YI-E HUANG $^{1,2^{*}}$, ZHI-HAN TANG $^{1 *}$, WEI XIE ${ }^{1}$, XIN-TIAN SHEN $^{1,2}$, MI-HUA LIU $^{1}$, \\ XIANG-PING PENG ${ }^{1}$, ZHAN-ZHI ZHAO ${ }^{1}$, DE-BO NIE ${ }^{1}$, LU-SHAN LIU ${ }^{1}$ and ZHI-SHENG JIANG ${ }^{1}$ \\ ${ }^{1}$ Institute of Cardiovascular Disease and Key Laboratory for Arteriosclerology of Hunan Province, \\ University of South China, Hengyang, Hunan 421001; ${ }^{2}$ Huaihua Medical College, Huaihua, Hunan 418000, P.R. China
}

Received June 6, 2012; Accepted September 18, 2012

DOI: $10.3892 /$ etm.2012.733

\begin{abstract}
Hydrogen sulfide $\left(\mathrm{H}_{2} \mathrm{~S}\right)$, produced by cystanthionine$\gamma$-lysase (CSE) in the cardiovascular system, has been suggested to be the third gasotransmitter in addition to nitric oxide (NO) and carbon monoxide (CO). The present study aimed to investigate the role of $\mathrm{H}_{2} \mathrm{~S}$ in ischemic postconditioning (IPO) during the early period of reperfusion. IPO with 6 episodes of $10 \mathrm{sec}$ reperfusion followed by 6 episodes of $10 \mathrm{sec}$ ischemia (IPO 2') was administered when reperfusion was initiated. Cardiodynamics and the concentration of $\mathrm{H}_{2} \mathrm{~S}$ were measured at $1,2,3,4,5,10,20,30,60,90$ and $120 \mathrm{~min}$ of reperfusion. Lactate dehydrogenase (LDH) levels and infarct size were determined at the end of the reperfusion. The concentration of $\mathrm{H}_{2} \mathrm{~S}$ was stable during the whole experiment in the control group, whereas it reached a peak at the first minute of reperfusion in the ischemia-reperfusion (IR) group. The concentration of $\mathrm{H}_{2} \mathrm{~S}$ at the first minute of reperfusion in the IPO 2' group was higher compared to that of the IR group, which correlated with cardioprotection including improved heart contractile function and reduced infarct size and LDH levels. However, the above effects of IPO 2' were attenuated by pre-treatment with blockade of endogenous $\mathrm{H}_{2} \mathrm{~S}$ production with DL-propargylglycine for $20 \mathrm{~min}$ prior to global ischemia. Furthermore, we found that other forms of IPO, IPO commencing at 1 min after reperfusion (delayed IPO) or lasting only for $1 \mathrm{~min}$ (IPO 1'), failed to increase the concentration of $\mathrm{H}_{2} \mathrm{~S}$ and protect the myocardium. We conclude that the peak of endogenous $\mathrm{H}_{2} \mathrm{~S}$ in the early reperfusion phase is the key to cardioprotection induced by IPO.
\end{abstract}

Correspondence to: Professor Zhi-Sheng Jiang, Institute of Cardiovascular Disease, Key Laboratory for Arteriosclerology of Hunan Province, University of South China, 28 West Changsheng Road, Hengyang, Hunan 421001, P.R. China

E-mail: zsjianglab@yahoo.cn

${ }^{*}$ Contributed equally

Key words: hydrogen sulfide, postconditioning, ischemia-reperfusion injury, cardioprotection

\section{Introduction}

Ischemic postconditioning (IPO) is defined as a short series of repetitive cycles of brief reperfusion and re-occlusion of the coronary artery applied immediately at the onset of reperfusion. Its cardioprotective effects include the reduction of infarct size and the improvement of coronary artery endothelial dysfunction and neutrophil accumulation in the area at risk $(1,2)$. However, the effects of IPO are determined by the time frame of the early reperfusion. A previous study (3) has reported that the infarct-sparing advantage of IPO and the reduction in malondialdehyde (MDA) and dihydroethidium (DHE) fluorescence intensity were lost when IPO was delayed for the 1-min period of reperfusion. These data suggest that the early moments of reperfusion during which immediate IPO is applied are crucial for its protective effects to take place. Cohen et al (4) proposed that the time frame for IPO was the first $2 \mathrm{~min}$ at the onset of reperfusion, as $1 \mathrm{~min}$ or delayed IPO was ineffective. Hausenloy et al (5) suggested that IPO may be mediated through the modulation of the mitochondrial permeability transition pore (mPTP), whose opening in the first few minutes of myocardial reperfusion mediates cell death. The significant burst of reactive oxygen species (ROS) and $\mathrm{Ca}^{2+}$ overload during the first minute of reperfusion are important manifestations of ischemic reperfusion injury (6), whereas IPO treatment reduces reperfusion injury by decreasing ROS generation and attenuating mitochondrial $\mathrm{Ca}^{2+}$ concentrations. However, the exact mechanisms for IPO warrant further investigation, as the ideal time frame for IPO has not yet been fully elucidated.

Hydrogen sulfide $\left(\mathrm{H}_{2} \mathrm{~S}\right)$, as an endogenous material, has been characterized as the third gasotransmitter besides nitric oxide (NO) and carbon monoxide (CO) (7). In the cardiovascular system, $\mathrm{H}_{2} \mathrm{~S}$ is predominantly generated by cystathionine- $\gamma$ lyase (CSE) $(7,8)$. CSE mRNA expression has been reported to be higher in the rat myocardium than in the thoracic aorta, with enzyme activity in the naïve myocardium being $19 \mathrm{nmol} /$ min/g protein (9). The level of $\mathrm{H}_{2} \mathrm{~S}$ detected in rat serum was $46 \mu \mathrm{M}(10)$. Thus, the heart is constantly bathed in a considerable amount of $\mathrm{H}_{2} \mathrm{~S}$ generated by the cardiac myocytes. Previously, it has been reported that the concentration of endogenous $\mathrm{H}_{2} \mathrm{~S}$ in plasma and myocardial tissue was significantly decreased in 
isoproterenol-induced myocardial injury $(11,12)$. Additionally, $\mathrm{H}_{2} \mathrm{~S}$ has been shown to protect the heart from myocardial ischemia-reperfusion (IR) injury in various studies (13-16). Furthermore, endogenous $\mathrm{H}_{2} \mathrm{~S}$ has been shown to mediate the cardioprotection induced by IPO (17). Despite abundant support for $\mathrm{H}_{2} \mathrm{~S}$ in the cardioprotective effects of IPO, the involvement of $\mathrm{H}_{2} \mathrm{~S}$ in the early reperfusion phase of IPO has not been studied. In the present study, we hypothesized that increased endogenous $\mathrm{H}_{2} \mathrm{~S}$ content in the coronary effluent during early reperfusion is indispensible for the beneficial effects of IPO.

\section{Materials and methods}

Materials. Our study conformed to the Guide for the Care and Use of Laboratory Animals published by the US National Institutes of Health (NIH Publications No. 85-23, revised 1996).

Male Sprague-Dawley rats (230-270 g; $n=40)$ were maintained in an air-filtered, temperature- $\left(20-22^{\circ} \mathrm{C}\right)$ and light(12-h light/dark cycle) controlled room, with a relative humidity of 50-52\%. Rats were fed with standard commercial pellets and water ad libitum. DL-propargylglycine (PAG) was obtained from Sigma-Aldrich Co. Ltd. (St. Louis, MO, USA).

Langendorff isolated heart model. Isolated heart experiments were performed as previously described (18). Sprague-Dawley rats were anesthetized with sodium pentobarbital $(50 \mathrm{mg} / \mathrm{kg})$. After a midline sternotomy, the hearts were rapidly excised into ice-cold heparinized $(5 \mathrm{U} / \mathrm{ml})$ perfusate buffer. After removal of the lung and surrounding tissue, the aorta was rapidly cannulated with a 20 -gauge, blunt-ended needle, and retrograde coronary perfusion was initiated at a constant pressure of $80 \mathrm{mmHg}$ with modified Krebs-Henseleit buffer containing: $120 \mathrm{mM} \mathrm{NaCl} ; 25 \mathrm{mM} \mathrm{NaHCO}{ }_{3} ; 11 \mathrm{mM}$ D-Glucose; $4.7 \mathrm{mM}$ $\mathrm{KCl} ; 1.2 \mathrm{mM} \mathrm{MgSO}_{4} ; 1.2 \mathrm{mM} \mathrm{KH}_{2} \mathrm{PO}_{4}$; and $2.5 \mathrm{mM} \mathrm{CaCl}_{2}$, $\mathrm{pH}$ 7.4). The perfusate buffer was saturated with a $95 \% \mathrm{O}_{2}$ and $5 \% \mathrm{CO}_{2}$ gas mixture at $37^{\circ} \mathrm{C}$ before use. A latex balloon was inserted into the left ventricle via the left atrium, inflated with distilled water and connected to Maclab System (Maclab, AD Instruments, Ltd., Colarado Springs, CO, USA). The left ventricular end diastolic pressure was set between 5 and $10 \mathrm{~mm}$ $\mathrm{Hg}$. The balloon volume was unchanged throughout the experiment. Cardiodynamic function for left ventricular developed pressure (LVDP), rate pressure product (RPP), maximum gradient during systoles $\left(+\mathrm{dP}_{\mathrm{P}} / \mathrm{dt}_{\max }\right)$ and minimum gradient during diastoles $\left(-\mathrm{dP}_{\mathrm{dt}}\right.$ max $)$ of the heart were continuously monitored with a computer-based data acquisition system. Prior to each experimental protocol, the isolated hearts were allowed to stabilize for $20 \mathrm{~min}$ at $37^{\circ} \mathrm{C}$. Hearts were excluded from further study if after stabilization they failed to develop steady sinus rhythm or their left ventricular developed pressures were $<60 \mathrm{~mm} \mathrm{Hg}$. Isolated rat hearts were perfused and stabilized for at least $20 \mathrm{~min}$ before recording data. Global ischemia was mimicked by stopping the perfusion of KrebsHenseleit buffer, i.e., perfusion rate $=0 \mathrm{ml} / \mathrm{min}$. The hearts were randomly divided into 7 groups according to the perfusion protocol as shown in Fig. 1. The control (CON) and PAG groups served as the negative controls in this study. Rat hearts were randomly divided into 7 groups ( $n=5$, each group): i) $\mathrm{CON}$, 190 min duration of perfusion; ii) PAG, treated with $2 \mathrm{mM}$ PAG (the inhibition of endogenous $\mathrm{H}_{2} \mathrm{~S}$ synthesis) for $20 \mathrm{~min}$

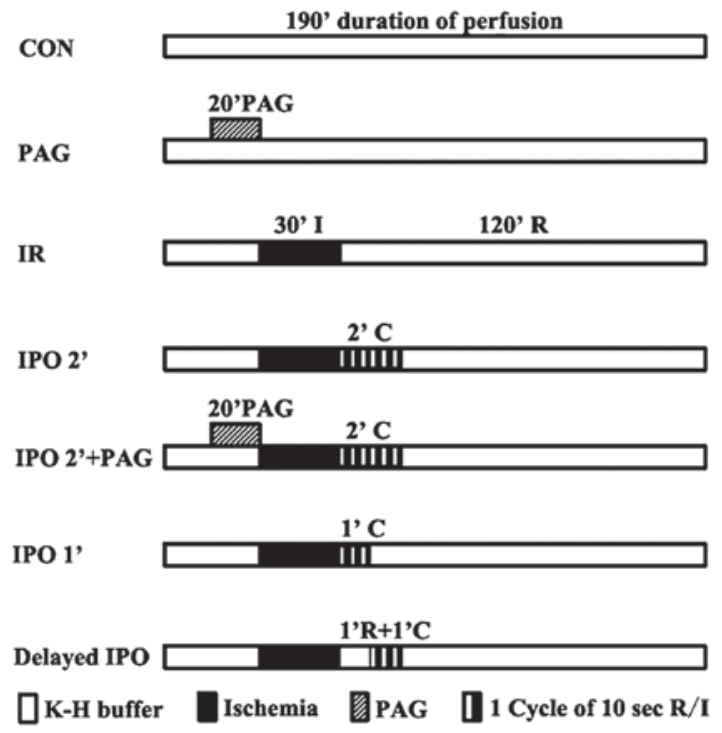

Figure 1. Schematic presentation of the experimental treatment protocol. White field, Krebs solution; black field, no-flow ischemia. DL-propargylglycine (PAG), an inhibitor $\mathrm{H}_{2} \mathrm{~S}$ of synthesis, was administered 20 min prior to ischemic treatment. CON, control; IPO, ischemic postconditioning; I, ischemia; R, reperfusion; $\mathrm{C}$, cycles.

after 20 min stabilization, followed by perfusion for $150 \mathrm{~min}$; iii) IR, after 40 min stabilization, hearts were administered $30 \mathrm{~min}$ global ischemia, followed by reperfusion for $120 \mathrm{~min}$; iv) IPO 2', 6 cycles of $10 \mathrm{sec}$ reperfusion followed by 6 cycles of $10 \mathrm{sec}$ ischemia immediately upon reperfusion (2 min total intervention); v) IPO 2' + PAG: hearts were pre-treated with $2 \mathrm{mM}$ PAG for $20 \mathrm{~min}$ prior to global ischemia and IPO treatment for $2 \mathrm{~min}$; vi) IPO 1', the algorithm of IPO was repeated for 3 cycles ( 1 min total intervention); vii) delayed IPO, hearts were reperfused for $1 \mathrm{~min}$, after which the 6 cycles of IPO 2' algorithm were applied.

$\mathrm{H}_{2} \mathrm{~S}$ concentration measurement. The coronary venous effluent at 1,2, 3, 4, 5, 10, 20, 30, 60, 90 and 120 min of reperfusion was collected from each group. Samples were diluted with deionised water (final volume, $500 \mu \mathrm{l}$ ) and added to a $1.5-\mathrm{ml}$ tube containing zinc acetate $(1 \% \mathrm{w} / \mathrm{v}, 250 \mu \mathrm{l})$ to trap $\mathrm{H}_{2} \mathrm{~S}(13,19)$. Subsequently, N,N-dimethyl-p-phenylenediamine sulphate $(20 \mu \mathrm{M} ; 133 \mu \mathrm{l})$ in $7.2 \mathrm{~mol} / \mathrm{l}$ hydrogen chloride $(\mathrm{HCl})$ was added, followed by the addition of $\mathrm{FeCl}_{3}(30 \mu \mathrm{M} ; 133 \mu \mathrm{l})$ in $1.2 \mathrm{~mol} / \mathrm{l}$ $\mathrm{HCl}$. Thereafter, trichloroacetic acid $(10 \% \mathrm{w} / \mathrm{v}, 250 \mu \mathrm{l})$ was used to precipitate any proteins present. Samples were cleared by centrifugation $(10,000 \mathrm{xg}$ ) and the A670 measured on aliquots from the resulting supernatant (300 $\mu \mathrm{l})$ using an ultraviolet spectrometer 2450 (Shimadzu Corp., Kyoto, Japan). Various concentrations of sodium hydrogen sulfide (NaHS) were used to plot standard curve and calculate the concentration of $\mathrm{H}_{2} \mathrm{~S}$ in samples $\left(\mu \mathrm{mol} \cdot \mathrm{l}^{-1}\right)$.

Infarct size. Infarct size was assessed by triphenyltetrazolium chloride (TTC) staining (20). At the end of the IR protocol, the hearts were cut into 2-mm transverse slices. After incubation in $1 \%$ TTC in PBS (pH 7.4) solution for $30 \min \left(37^{\circ} \mathrm{C}\right)$, the sections were immersed in formalin $(4 \% \mathrm{w} / \mathrm{v})$ for another $30 \mathrm{~min}$. Images were scanned into a computer and total ventricular 

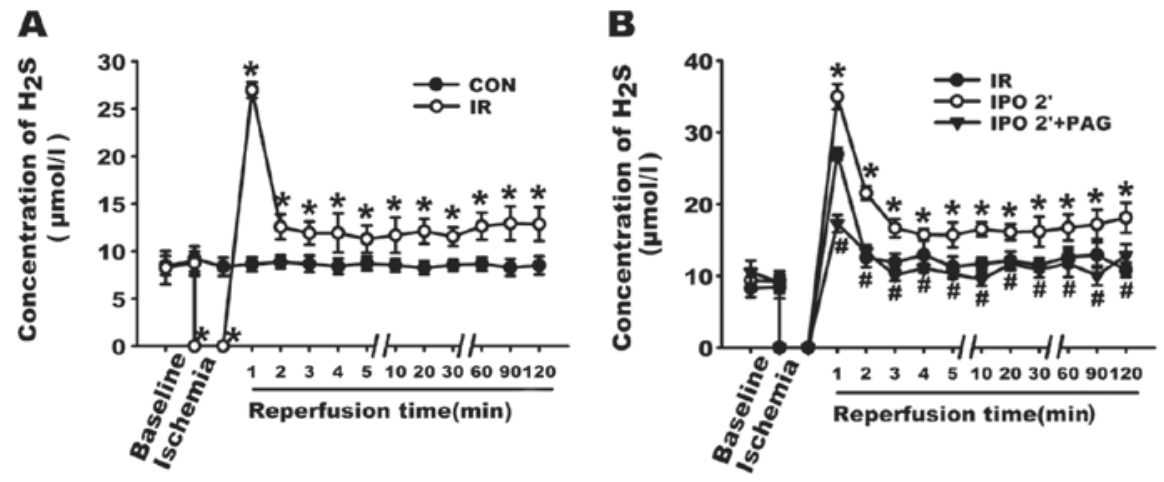

Figure 2. Change in $\mathrm{H}_{2} \mathrm{~S}$ concentration (mean $\pm \mathrm{SD}$ ). (A) Effect of ischemia-reperfusion (IR) on $\mathrm{H}_{2} \mathrm{~S}$ concentration. (B) Effect of ischemic postconditioning (IPO) 2' on concentration of hydrogen sulfide $\left(\mathrm{H}_{2} \mathrm{~S}\right)$ in the presence and absence of DL-propargylglycine (PAG). ${ }^{*} \mathrm{P}<0.05$, compared with control (CON) (A) or IR (B) group; ${ }^{*} \mathrm{P}<0.05$, compared with IPO 2 ' group. $\mathrm{n}=5$.

area as well as infarct area were determined by computerized planimetry (Adobe Photoshop, version CS3). The infarct size was expressed as a percentage of the total ventricular area (\%).

Lactate dehydrogenase ( $L D H)$ content in coronary efflux. The LDH content in the coronary effluent was used as a biochemical marker of cardiomyocyte injury. For each heart, a baseline sample of coronary effluent was collected from the superfusate bath overflow during the final minute of equilibration (prior to the onset of global ischemia). Coronary effluent was then collected at the end of $120 \mathrm{~min}$ of reperfusion and a $1.5-\mathrm{ml}$ aliquot was stored on ice for assay within $24 \mathrm{~h}$. LDH content was determined with an automated spectrophotometric clinical assay using an ACE Chemistry Analyzer (Alfa Wassermann Inc., West Caldwell, NJ, USA).

Statistical analysis. All results are expressed as the means \pm SD. Statistical analysis was performed using SPSS 13.0 software for Windows. Differences between groups were analyzed by one-way ANOVA followed by the Student Newman-Keuls test. $\mathrm{P}<0.05$ was considered to indicate a statistically significant difference.

\section{Results}

Changes in $\mathrm{H}_{2} \mathrm{~S}$ concentration in the coronary effluent. $\mathrm{H}_{2} \mathrm{~S}$ is synthesized mainly by CSE in the cardiovascular system. However, it is unclear whether $\mathrm{H}_{2} \mathrm{~S}$ can still be generated in ischemic heart. As shown in Fig. 2A, the concentration of $\mathrm{H}_{2} \mathrm{~S}$ in the CON group was stable, ranging from $8.28 \pm 0.89$ to $9.21 \pm 1.32 \mu \mathrm{mol} / 1$. By contrast, after 30 -min global ischemia, the concentration of $\mathrm{H}_{2} \mathrm{~S}$ in the coronary effluent in the first minute of reperfusion reached a peak $(26.96 \pm 0.83 \mu \mathrm{mol} / \mathrm{l})$ of almost 4-fold the level of the baseline, which strongly suggests that during the $30 \mathrm{~min}$ of global ischemia, $\mathrm{H}_{2} \mathrm{~S}$ was still produced and accumulated in the myocardium. On the basis of this result, we further examined the changes in $\mathrm{H}_{2} \mathrm{~S}$ concentration in the coronary effluents. As shown in Fig. 2B, in the first minute after the resumption of flow, the concentration of $\mathrm{H}_{2} \mathrm{~S}$ in the IR, IPO 2', IPO 2' + PAG group increased to $26.96 \pm 0.83,34.97 \pm 1.74$ and $17.26 \pm 1.20 \mu \mathrm{mol} / 1$, respectively. Compared with the IR group, the concentration of $\mathrm{H}_{2} \mathrm{~S}$ in the coronary effluent was significantly increased in the IPO 2 ' group $(\mathrm{P}<0.05)$, indicating that the IPO 2' treatment further increased the level of $\mathrm{H}_{2} \mathrm{~S}$ in the coronary effluent during the first minute of reperfusion. However, in the IPO 2' + PAG group, pre-treatment with PAG for $20 \mathrm{~min}$ prior to global ischemia abolished the effect of the IPO 2 ' treatment on the content of $\mathrm{H}_{2} \mathrm{~S}$ during the first minute of reperfusion. It should be noted that during the entire reperfusion process, the concentration of $\mathrm{H}_{2} \mathrm{~S}$ in the coronary effluent in the IPO 2' group was significantly higher than that in the IR and IPO 2' + PAG group (all p<0.05).

Changes in cardiodynamic function. The effect of PAG on cardiodynamic function in the isolated rat hearts was examined. As shown in Fig. 3, the administration of PAG (2 mM) alone did not significantly influence cardiodynamic function including LVDP, RPP, $+\mathrm{dP} / \mathrm{dt}_{\max }$ and $-\mathrm{dP} / \mathrm{dt}_{\max }$. PAG was therefore used in the following experiments to determine the involvement of endogenous $\mathrm{H}_{2} \mathrm{~S}$ in the cardioprotection induced by IPO $2^{\prime}$ treatment.

Cardiac mechanical function including LVDP, RPP, $\pm \mathrm{dp} / \mathrm{dt}_{\max }$ was measured to determine the involvement of endogenous $\mathrm{H}_{2} \mathrm{~S}$ in the cardioprotection induced by the IPO $2^{\prime}$ treatment. As shown in Fig. 4, the IPO 2' treatment exerted a significant cardioprotective effect with the recovery of cardiac function following ischemia compared with that of IR. The recoveries at $120 \mathrm{~min}$ of LVDP, $\mathrm{RPP},+\mathrm{dP} / \mathrm{dt}_{\max }$ and $-\mathrm{dP} / \mathrm{dt}_{\max }$ in IPO 2 ' group were 1.50, 1.76, 1.60 and 1.84-fold of the IR group, respectively (all $\mathrm{P}<0.05$ compared with $\mathrm{IR}, \mathrm{n}=5$ ). However, pre-treatment with $2 \mathrm{mM}$ PAG $20 \mathrm{~min}$ prior to global ischemia, which inhibited the production of endogenous $\mathrm{H}_{2} \mathrm{~S}$ prior to and during ischemia, significantly diminished the cardioprotective effect of the IPO 2' treatment by reducing LVDP, RPP, $+\mathrm{dP} / \mathrm{dt}_{\max }$ and $-\mathrm{dP} / \mathrm{dt}_{\text {max }}$ to $0.77,0.55,0.46$ and 0.39 -fold of the IPO 2 ' group, respectively (all $\mathrm{P}<0.05$ compared with IPO 2', n=5).

Changes in infarct size. As shown in Fig. 5, no significant differences in infarct size were observed between the CON and PAG group. While an infarct size of $41.8 \pm 6.2 \%$ was caused in the IR group, the infarct size was significantly decreased to $18.3 \pm 5.7 \%$ in the IPO $2^{\prime}$ group $(\mathrm{P}<0.05)$. However, $\mathrm{PAG}$ pre-treatment in the IPO 2 ' group resulted in an infarct size of $35.9 \pm 6.4 \%$. This was significantly increased when compared to the IPO 2' group $(\mathrm{P}<0.05)$, suggesting that PAG inhibited the cardioprotection observed by the IPO 2 ' treatment. 

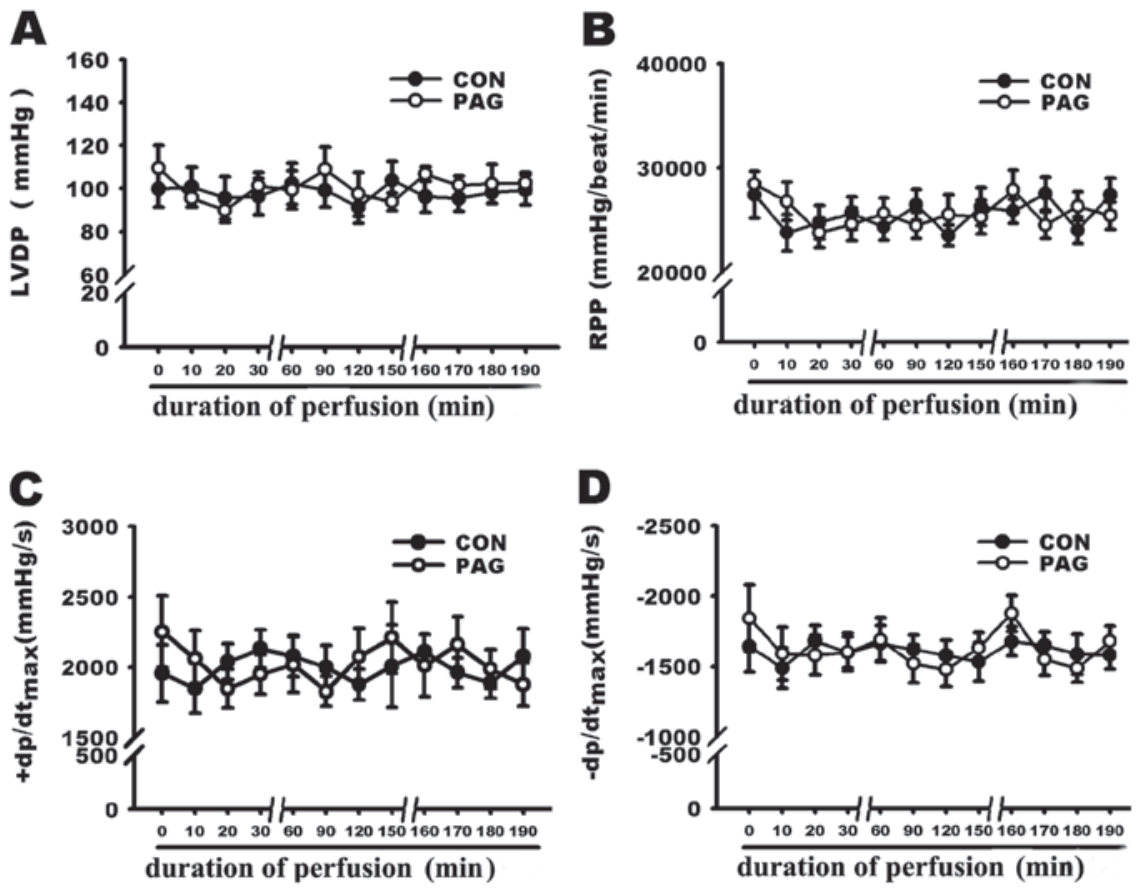

Figure 3. Effect of DL-propargylglycine (PAG) on cardiodynamics (mean \pm SD). Mean data of cardiodynamics showing that $2 \mathrm{mM}$ PAG alone did not alter the cardiodynamics significantly. (A) Left ventricular developed pressure (LVDP); (B) rate pressure product (RPP); (C) maximum gradient during systoles (+dP/ $\left.\mathrm{dt}_{\text {max }}\right)$; (D) minimum gradient during diastoles $\left(-\mathrm{dP}_{\mathrm{dt}} \mathrm{dt}_{\max }\right) \cdot \mathrm{n}=3$ or 4.
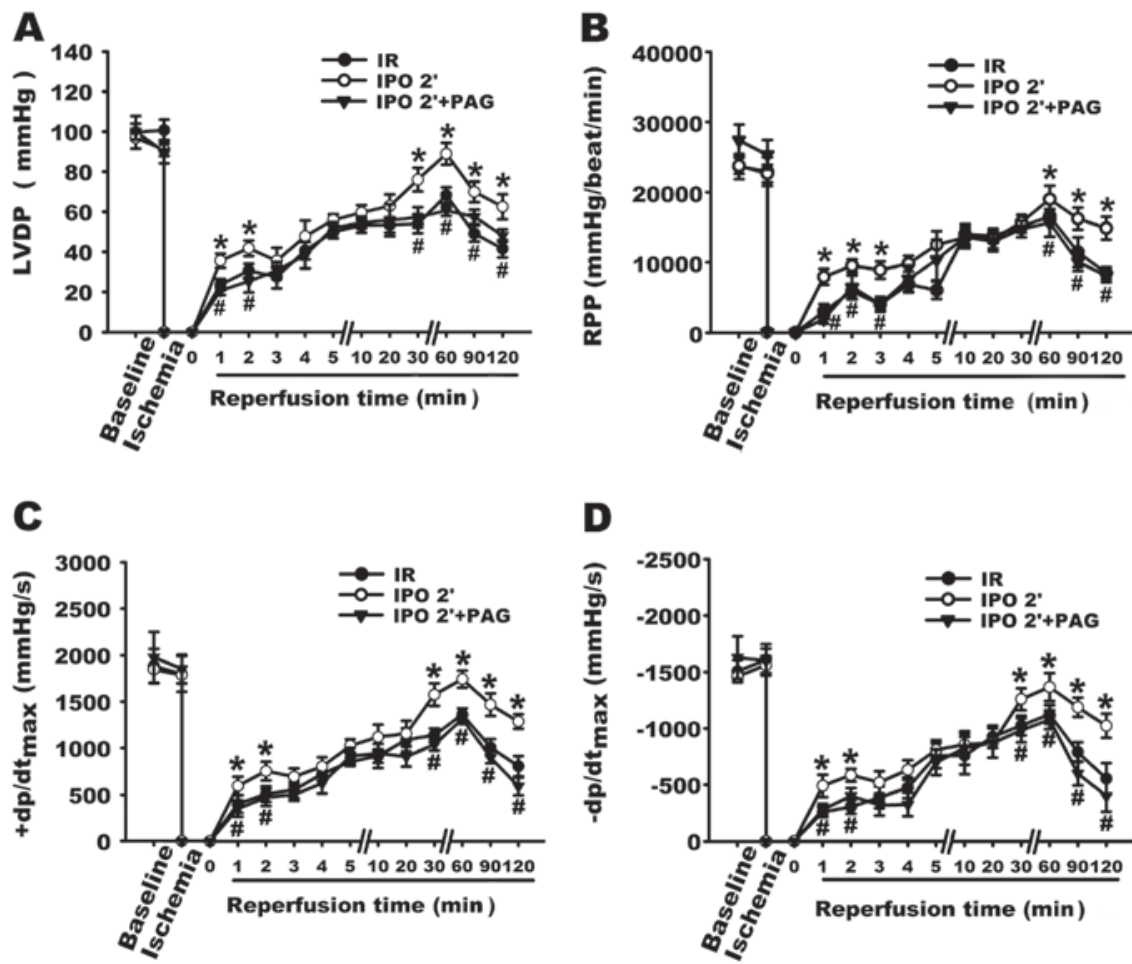

Figure 4. Effect of ischemic postconditioning (IPO) 2' on cardiodynamics in the presence or absence of DL-propargylglycine (PAG) (mean \pm SD). (A) Left ventricular developed pressure (LVDP); (B) rate pressure product (RPP); (C) maximum gradient during systoles (+dP/dt $\mathrm{max}_{\max }$; (D) minimum gradient during diastoles $\left(-\mathrm{dP}_{\mathrm{d}} \mathrm{dt}_{\max }\right)$. ${ }^{\mathrm{P}}<0.05$, compared with ischemia-reperfusion (IR) group; ${ }^{\prime \prime} \mathrm{P}<0.05$, compared with IPO 2' group. $\mathrm{n}=5$.

Changes in LDH levels in the coronary effluent. As shown in Fig. 6A, there were no significant differences in LDH levels in the coronary efflux between the CON and PAG groups. The LDH content in the coronary effluent at 120 min of reperfusion
(Fig. 6B) was significantly lower in the IPO 2' group compared to the IR group ( $31.60 \pm 1.95$ vs. $48.20 \pm 6.32 \mathrm{IU} / 1, \mathrm{P}<0.05)$. However, the LDH level was significantly increased in the IPO $2^{\prime}+$ PAG group $(58.20 \pm 8.06 \mathrm{IU} / \mathrm{l})$ compared to the IPO $2^{\prime}$ group $(\mathrm{P}<0.05)$. 

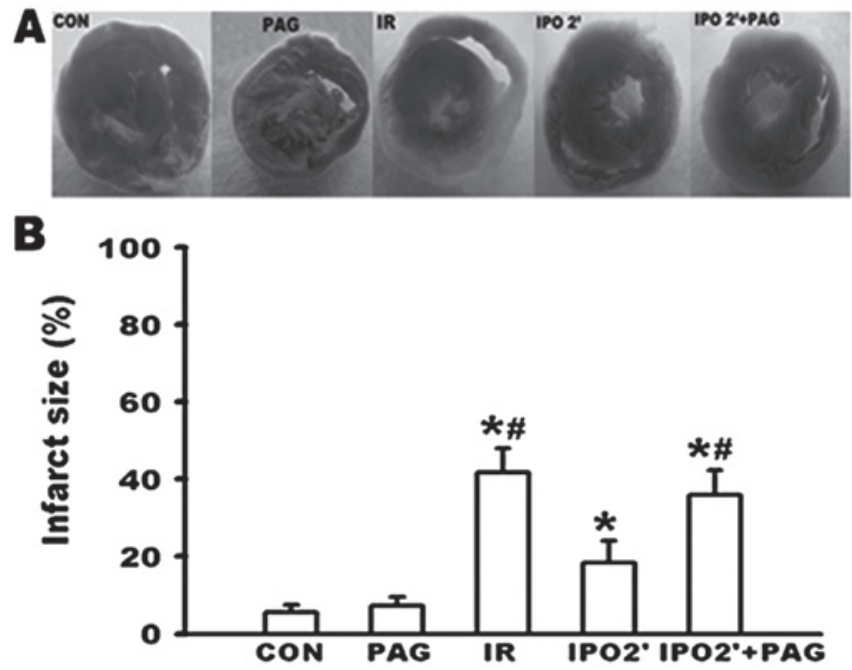

Figure 5. Effect of ischemic postconditioning (IPO) 2' on myocardial infarction in the presence or absence of DL-propargylglycine (PAG) (mean $\pm \mathrm{SD}$ ). (A) Representative photographs of infarcted heart slices stained with triphenyltetrazolium chloride. Infarcted tissue appears pale, while viable tissue stains red. (B) Mean data of infarct size (expressed as percentage of total ventricular area). ${ }^{\text {P }}<0.05$, compared with control $(\mathrm{CON})$ group; ${ }^{\#} \mathrm{P}<0.05$, compared with IPO 2 ' group. $n=5$ or 6 .
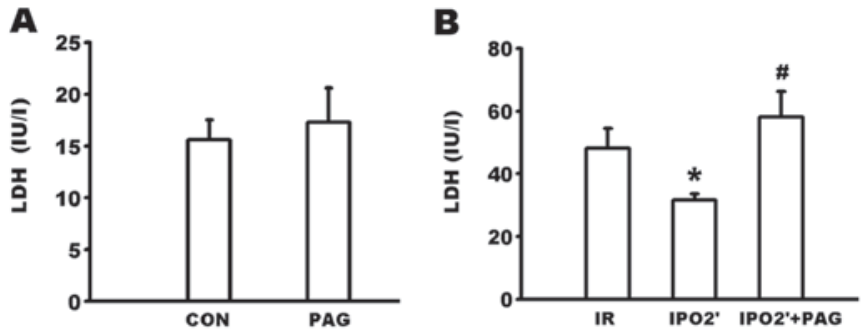

Figure 6. Change in lactate dehydrogenase (LDH) content in the coronary effluent (mean $\pm \mathrm{SD}$ ). (A) DL-propargylglycine (PAG) alone had no significant effect on LDH content. (B) Effect of ischemic postconditioning (IPO) 2' on LDH content in the presence and absence of PAG. " $\mathrm{P}<0.05$, compared with ischemia-reperfusion (IR) group; ${ }^{\prime} \mathrm{P}<0.05$, compared with IPO 2' group. $\mathrm{n}=5$.

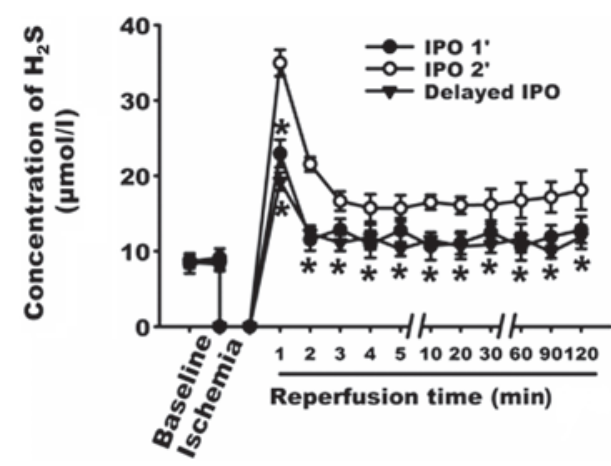

Figure 7. Effect of ischemic postconditioning (IPO) 1 ' and delayed IPO on the concentration of hydrogen sulfide $\left(\mathrm{H}_{2} \mathrm{~S}\right)($ mean $\pm \mathrm{SD}) .{ }^{*} \mathrm{P}<0.05$, compared with IPO $2^{\prime}$ group. $n=5$.

Effect of IPO I' and Delayed IPO. As shown in Fig. 7, the concentrations of $\mathrm{H}_{2} \mathrm{~S}$ in the IPO 1' and the delayed IPO groups were decreased when compared to the IPO 2' group. The cardio-
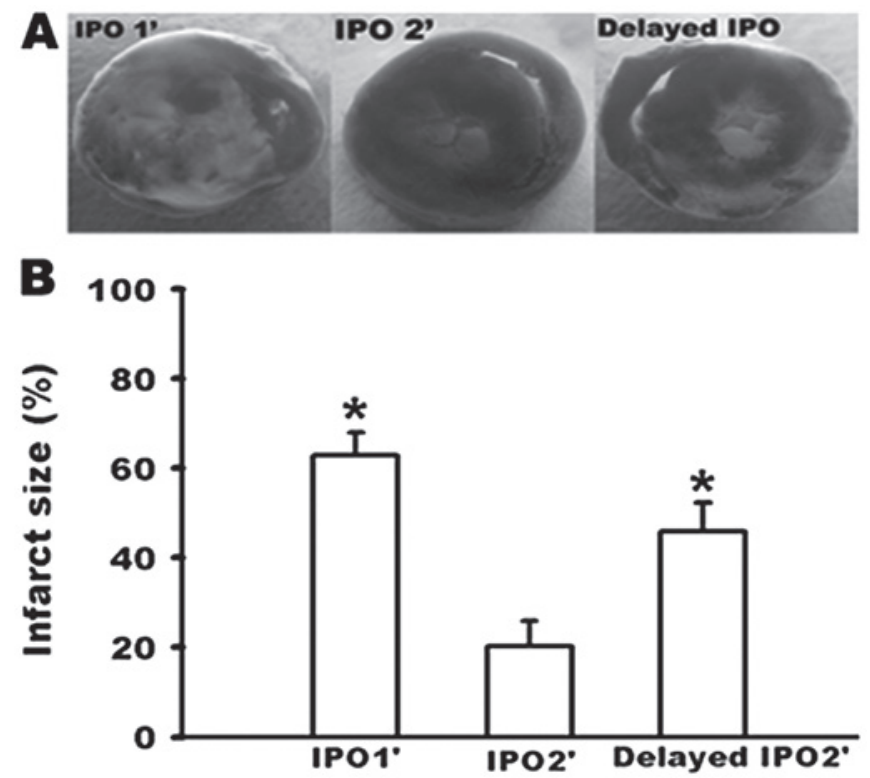

Figure 8. Effect of ischemic postconditioning (IPO) 1' and delayed IPO on the infart size (mean \pm SD). (A) Representative photographs of infarcted heart slices stained with triphenyltetrazolium chloride. (B) Mean data of infarct size (expressed as percentage of total ventricular area). ${ }^{*} \mathrm{P}<0.05$, compared with IPO 2 ' group. $\mathrm{n}=4$ or 5 .

protective effects were reduced in the IPO 1' and the delayed IPO groups as represented by greater infarct size (Fig. 8) and lower recovery of cardiodynamic function (Fig. 9).

\section{Discussion}

The main objective of this study was to explore the role of endogenous $\mathrm{H}_{2} \mathrm{~S}$ in the cardioprotection induced by IPO during early reperfusion. We found that IPO 2' (IPO lasting for 2 min) significantly improved the heart contractile function and reduced multiple manifestations of IR injury, including infarct size and LDH levels. This is consistent with previous findings that IPO protects the heart from lethal IR injury when assessed by infarct size $(3,21,22)$, cardiodynamic performance $(23-26)$ and cellular injury biomarkers $(6,27)$.

The myocardium generates a considerable amount of $\mathrm{H}_{2} \mathrm{~S}$ under physiological conditions $(8,9)$; however, $\mathrm{H}_{2} \mathrm{~S}$ production is decreased upon ischemia treatment (19). In the present study, we demonstrated that the concentration of $\mathrm{H}_{2} \mathrm{~S}$ was stable throughout the entire experiment in the CON group, and its concentration reached a peak during the first minute of reperfusion in the IR group. This indicates that $\mathrm{H}_{2} \mathrm{~S}$ accumulates in the myocardium during the $30 \mathrm{~min}$ of global ischemia and is then washed out immediately during early reperfusion. In addition, during the first minute of reperfusion the concentration of $\mathrm{H}_{2} \mathrm{~S}$ in the IPO $2^{\prime}$ group was higher than that in the IR group, suggesting that intermittent reperfusion delayed the washout of $\mathrm{H}_{2} \mathrm{~S}$ during early reperfusion. On the other hand, $\mathrm{H}_{2} \mathrm{~S}$ in aqueous solution is dissociated into $\mathrm{HS}^{-}$and $\mathrm{H}^{+}$, which exist in equilibrium with each other. The proportion of undissociated $\mathrm{H}_{2} \mathrm{~S}$ under standard temperature conditions at physiological $\mathrm{pH}(7.4)$ is $30-33 \%(20,28)$, and the proportion increases as $\mathrm{pH}$ decreases. As shown in a previous study, acidotic status induced by ischemia is prolonged in IPO 2' (4), thus the lower 
A
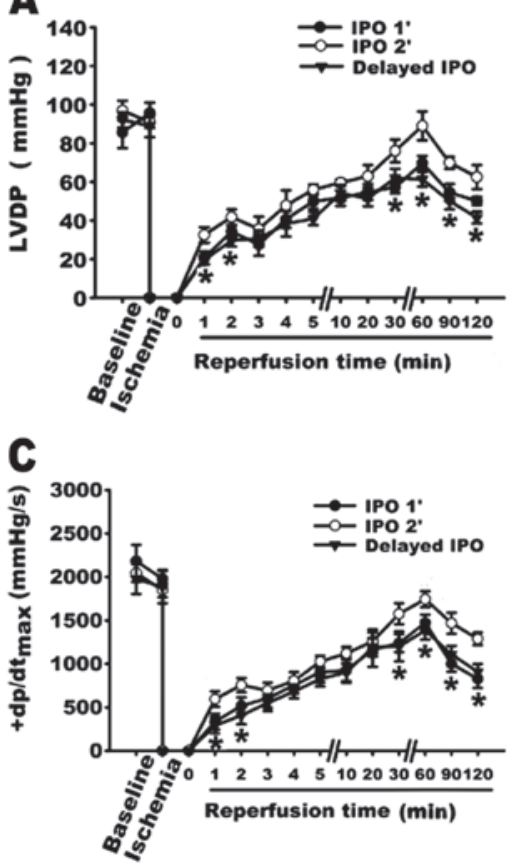

B

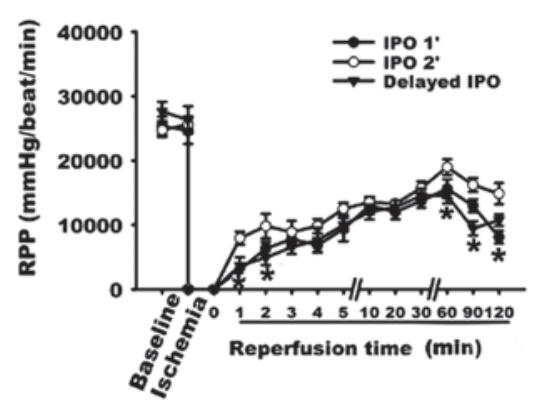

D

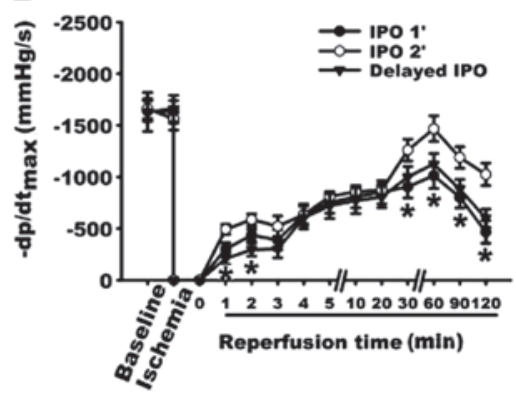

Figure 9. Effect of ischemic postconditioning (IPO) 1' and delayed IPO on cardiodynamics (mean \pm SD). (A) Left ventricular developed pressure (LVDP); (B) rate pressure product (RPP); (C) maximum gradient during systoles $\left(+\mathrm{dP}^{\mathrm{d}} \mathrm{dt}_{\max }\right)$; (D) minimum gradient during diastoles $\left(-\mathrm{dP}_{\mathrm{dt}}\right.$ max $)$. $\mathrm{P}<0.05$, compared with IPO 2' group. $n=5$.

$\mathrm{pH}$ status induced by IPO $2^{\prime}$ can further increase the concentration of $\mathrm{H}_{2} \mathrm{~S}$ at the onset of reperfusion.

It has been previously reported that the early phase of reperfusion may be the key to cardioprotection induced by $\operatorname{IPO}(3,4)$. Therefore, we designed other forms of IPO, IPO starting 1 min after reperfusion (delayed IPO) or lasting only $1 \mathrm{~min}$ (IPO 1'), to examine the important time frame of IPO 2'. Our data demonstrated that IPO 1' and delayed IPO failed to exert a cardioprotective effect, and with both treatments the peak of the $\mathrm{H}_{2} \mathrm{~S}$ concentration decreased simultaneously during the first minute of reperfusion. There may be 2 explanations for the lower concentration of $\mathrm{H}_{2} \mathrm{~S}$ during early reperfusion in both groups. Firstly, there was not enough time for $\mathrm{H}_{2} \mathrm{~S}$ accumulation during early reperfusion since IPO 1' lasted only $1 \mathrm{~min}$. $\mathrm{H}_{2} \mathrm{~S}$ was washed out immediately as the reperfusion was initiated, which resulted in reduced retention of $\mathrm{H}_{2} \mathrm{~S}$ at the onset of the reperfusion in delayed IPO. Secondly, during early reperfusion in both IPO 1' and delayed IPO, $\mathrm{pH}$ quickly returned to a neutral level. A lower $\mathrm{pH}$ is responsible for the generation of increased amounts of $\mathrm{H}_{2} \mathrm{~S}$ (4). Indeed, the time-relative changes of $\mathrm{H}_{2} \mathrm{~S}$ level are consistent with the critical time frame of the IPO effect. Therefore, our data suggest that IPO lasting only $2 \mathrm{~min}$ and commencing at the onset of reperfusion could preserve $\mathrm{H}_{2} \mathrm{~S}$ in order to mediate the cardioprotection invoked by IPO.

The accumulation of endogenous material during early reperfusion is one of the important mechanisms of IPO-mediated effects. The observations of Zhao et al (2) suggested that endogenous mechanisms are put into action within the first few minutes of reperfusion that attenuate reperfusion injury specifically. Kin et al (25) reported that IPO delays the washout of endogenous adenosine during the critical early moments of reperfusion, thereby increasing intravascular adenosine concentrations, which can activate adenosine receptors to elicit protection against myocardial infarction. In addition, previous studies $(29,30)$ have shown that with IPO maneuvers the heart releases autacoids that accumulate in an intermittent manner during early reperfusion and trigger pathways leading to a protected state. In the present study, we noted that the higher concentration of $\mathrm{H}_{2} \mathrm{~S}$ during early reperfusion in IPO $2^{\prime}$ was associated with improved recovery of contractile function, decreased infarct size and LDH level. However, the inhibition of endogenous $\mathrm{H}_{2} \mathrm{~S}$ synthesis by PAG (the specific and irreversible inhibitor of CSE) used $20 \mathrm{~min}$ prior to ischemic treatment notably inhibited the generation of $\mathrm{H}_{2} \mathrm{~S}$ and abolished the cardioprotective effects exerted by IPO 2'. Our data indicated that the increase in endogenous $\mathrm{H}_{2} \mathrm{~S}$ during early reperfusion contributes to the cardioprotective effects of IPO $2^{\prime}$.

There is a significant burst of oxygen-derived free radicals generated within the first minute of reperfusion peaking 4-7 min following the onset of reperfusion (6), which contribute to the IR injury. $\mathrm{H}_{2} \mathrm{~S}$ is a thiol that can interact with and 'scavenge' free radicals, including $\mathrm{ONOO}(31), \mathrm{H}_{2} \mathrm{O}_{2}$ (12) and $\mathrm{HOCl}$ (32). Therefore, the potential cellular mechanisms for $\mathrm{H}_{2} \mathrm{~S}$-mediated early cardioprotection invoked by IPO 2 ' may involve the reduction of the peak generation of ROS occurring during the first minutes of reperfusion. In addition, a previous study has shown that $\mathrm{H}_{2} \mathrm{~S}$, the $\mathrm{K}_{\text {ATP }}$ channel opener, was involved in cardiac protection (33). For this reason we presumed that $\mathrm{H}_{2} \mathrm{~S}$ may protect the ischemic myocardum by opening $\mathrm{K}_{\mathrm{ATP}}$ channels. However, the exact mechanisms remain uncertain in the present study. It is not known whether deleterious mechanisms are attenuated, or whether beneficial mechanisms are triggered by $\mathrm{H}_{2} \mathrm{~S}$. This is a limitation of our present study and warrants further investigation. 
In conclusion, this study demonstrates that endogenous $\mathrm{H}_{2} \mathrm{~S}$ mediates the cardioprotection induced by IPO during early reperfusion. $\mathrm{H}_{2} \mathrm{~S}$ may be considered to protect by 'pharmacological IPO' thus offering greater opportunity for protection clinically, such as at the time of thrombolysis, percutaneous transluminal coronary angioplasty (PTCA) and coronary artery bypass grafting (CABG). This study provides an impetus for further investigation into the synthesis of a drug that can release $\mathrm{H}_{2} \mathrm{~S}$. If the certain protection of $\mathrm{H}_{2} \mathrm{~S}$ were proved clinically, then ischemia-reperfusion injury could be attenuated by simply administering an oral medication that released $\mathrm{H}_{2} \mathrm{~S}$.

\section{Acknowledgements}

This study was supported by the National Natural Science Foundation of China (30570766, 30971169, 81170277; ZS Jiang) and Aid Program for Science and Techology Innovative Research Team in Higher Educational Institutions (2008-244; ZS Jiang) of Hunan Province.

\section{References}

1. Na HS, Kim YI, Yoon YW, Han HC, Nahm SH and Hong SK: Ventricular premature beat-driven intermittent restoration of coronary blood flow reduces the incidence of reperfusion-induced ventricular fibrillation in a cat model of regional ischemia. Am Heart J 132: 78-83, 1996.

2. Zhao ZQ, Corvera JS, Halkos ME, et al: Inhibition of myocardial injury by ischemic postconditioning during reperfusion: comparison with ischemic preconditioning. Am J Physiol Heart Circ Physiol 285: H579-588, 2003.

3. Kin H, Zhao ZQ, Sun HY, et al: Postconditioning attenuates myocardial ischemia-reperfusion injury by inhibiting events in the early minutes of reperfusion. Cardiovasc Res 62: 74-85, 2004

4. Cohen MV, Yang XM and Downey JM: The pH hypothesis of postconditioning: staccato reperfusion reintroduces oxygen and perpetuates myocardial acidosis. Circulation 115: 1895-1903, 2007.

5. Hausenloy DJ, Duchen MR and Yellon DM: Inhibiting mitochondrial permeability transition pore opening at reperfusion protects against ischaemia-reperfusion injury. Cardiovase Res 60: 617-625, 2003

6. Sun HY, Wang NP, Kerendi F, et al: Hypoxic postconditioning reduces cardiomyocyte loss by inhibiting ROS generation and intracellular $\mathrm{Ca}^{2+}$ overload. Am J Physiol Heart Circ Physiol 288: H1900-1908, 2005.

7. Wang R: Two's company, three's a crowd: can $\mathrm{H}_{2} \mathrm{~S}$ be the third endogenous gaseous transmitter? Faseb J 16: 1792-1798, 2002.

8. Szabo C: Hydrogen sulphide and its therapeutic potential. Nat Rev Drug Discov 6: 917-935, 2007.

9. Geng B, Yang J, Qi Y, et al: $\mathrm{H}_{2} \mathrm{~S}$ generated by heart in rat and its effects on cardiac function. Biochem Biophys Res Commun 313: 362-368, 2004

10. Zhao W, Zhang J, Lu Y and Wang R: The vasorelaxant effect of $\mathrm{H}(2) \mathrm{S}$ as a novel endogenous gaseous K(ATP) channel opener. Embo J 20: 6008-6016, 2001.

11. Yong QC, Pan TT, Hu LF and Bian JS: Negative regulation of beta-adrenergic function by hydrogen sulphide in the rat hearts. $\mathrm{J}$ Mol Cell Cardiol 44: 701-710, 2008.

12. Geng B, Chang L, Pan C, et al: Endogenous hydrogen sulfide regulation of myocardial injury induced by isoproterenol. Biochem Biophys Res Commun 318: 756-763, 2004.

13. Elrod JW, Calvert JW, Morrison J, et al: Hydrogen sulfide attenuates myocardial ischemia-reperfusion injury by preservation of mitochondrial function. Proc Natl Acad Sci USA 104: 15560-15565, 2007.

14. Johansen D, Ytrehus K and Baxter GF: Exogenous hydrogen sulfide $\left(\mathrm{H}_{2} \mathrm{~S}\right)$ protects against regional myocardial ischemiareperfusion injury - evidence for a role of K ATP channels. Basic Res Cardiol 101: 53-60, 2006.
15. Sivarajah A, McDonald MC and Thiemermann C: The production of hydrogen sulfide limits myocardial ischemia and reperfusion injury and contributes to the cardioprotective effects of preconditioning with endotoxin, but not ischemia in the rat. Shock 26: 154-161, 2006.

16. Zhu YZ, Wang ZJ, Ho P, et al: Hydrogen sulfide and its possible roles in myocardial ischemia in experimental rats. J Appl Physiol 102: 261-268, 2007.

17. Yong QC, Lee SW, Foo CS, Neo KL, Chen X and Bian JS: Endogenous hydrogen sulphide mediates the cardioprotection induced by ischemic postconditioning. Am J Physiol Heart Circ Physiol 295: H1330-H1340, 2008.

18. Morrison RR, Talukder MA, Ledent C and Mustafa SJ: Cardiac effects of adenosine in $\mathrm{A}(2 \mathrm{~A})$ receptor knockout hearts: uncovering A(2B) receptors. Am J Physiol Heart Circ Physiol 282: H437-H444, 2002.

19. Bian JS, Yong QC, Pan TT, et al: Role of hydrogen sulfide in the cardioprotection caused by ischemic preconditioning in the rat heart and cardiac myocytes. J Pharmacol Exp Ther 316: 670-678, 2006.

20. Zhu YZ, Chong CL, Chuah SC, et al: Cardioprotective effects of nitroparacetamol and paracetamol in acute phase of myocardial infarction in experimental rats. Am J Physiol Heart Circ Physiol 290: H517-H524, 2006.

21. Darling CE, Jiang R, Maynard M, Whittaker P, Vinten-Johansen J and Przyklenk K: Postconditioning via stuttering reperfusion limits myocardial infarct size in rabbit hearts: role of ERK1/2. Am J Physiol Heart Circ Physiol 289: H1618-1626, 2005.

22. Yang XM, Philipp S, Downey JM and Cohen MV: Postconditioning's protection is not dependent on circulating blood factors or cells but involves adenosine receptors and requires PI3-kinase and guanylyl cyclase activation. Basic Res Cardiol 100: 57-63, 2005.

23. Crisostomo PR, Wang M, Wairiuko GM, Terrell AM and Meldrum DR: Postconditioning in females depends on injury severity. J Surg Res 134: 342-347, 2006.

24. Fantinelli JC and Mosca SM: Comparative effects of ischemic pre and postconditioning on ischemia-reperfusion injury in spontaneously hypertensive rats (SHR). Mol Cell Biochem 296: 45-51, 2007.

25. Kin H, Zatta AJ, Lofye MT, et al: Postconditioning reduces infarct size via adenosine receptor activation by endogenous adenosine. Cardiovasc Res 67: 124-133, 2005.

26. Zhu M, Feng J, Lucchinetti E, et al: Ischemic postconditioning protects remodeled myocardium via the PI3K-PKB/Akt reperfusion injury salvage kinase pathway. Cardiovasc Res 72: $152-162,2006$.

27. Wang HC, Zhang HF, Guo WY, et al: Hypoxic postconditioning enhances the survival and inhibits apoptosis of cardiomyocytes following reoxygenation: role of peroxynitrite formation. Apoptosis 11: 1453-1460, 2006.

28. Dombkowski RA, Russell MJ and Olson KR: Hydrogen sulfide as an endogenous regulator of vascular smooth muscle tone in trout. Am J Physiol Regul Integr Comp Physiol 286: R678-R685, 2004.

29. Penna C, Mancardi D, Rastaldo R, Losano G and Pagliaro P: Intermittent activation of bradykinin $\mathrm{B} 2$ receptors and mitochondrial KATP channels trigger cardiac postconditioning through redox signaling. Cardiovasc Res 75: 168-177, 2007.

30. Weihrauch D, Krolikowski JG, Bienengraeber M, Kersten JR, Warltier DC and Pagel PS: Morphine enhances isofluraneinduced postconditioning against myocardial infarction: the role of phosphatidylinositol-3-kinase and opioid receptors in rabbits. Anesth Analg 101: 942-949, 2005.

31. Whiteman M, Armstrong JS, Chu SH, et al: The novel neuromodulator hydrogen sulfide: an endogenous peroxynitrite 'scavenger'? J Neurochem 90: 765-768, 2004.

32. Whiteman M, Cheung NS, Zhu YZ, et al: Hydrogen sulphide: a novel inhibitor of hypochlorous acid-mediated oxidative damage in the brain? Biochem Biophys Res Commun 326: 794-798, 2005.

33. Hassouna A, Matata BM and Galinanes M: PKC-epsilon is upstream and PKC-alpha is downstream of mitoKATP channels in the signal transduction pathway of ischemic preconditioning of human myocardium. Am J Physiol Cell Physiol 287: C1418-C1425, 2004. 